\title{
Considerações sobre a Psychanalyse
}

\author{
Delo doutorando Mauricio Dereira Lima.
}

$\mathbf{E}^{\mathrm{S}}$ STAS considerações pouco aproveitarão aos que se queiram iniciar em psychanalyse. Nada, aos especialistas. Dedico-as aos que não se interessam pelo assumpto.

\section{$* * *$}

Machado de Assis, nos seus "lazeres do officio" tinha concepções freudianas sobre o estylo. Um casamento de palavras, como se lê no conto "O conego ou a metaphysica do estylo" Um substantivo e um adjectivo, Sylvio e Sylvia, amam-se e procuram-se no inconsciente de um conego, que está a compor um sermão. Um tropismo irresistivel fal-os vencerem todos os obstaculos que se oppõem ao seu encontro. Avistam-se, finalmente, abraçam-se e seguem pelo sermão do conego, unidinhos, cantando o Cantico dos Canticos, e constituindo o estylo.

Não é provavel que o nosso escriptor estivesse ao par das theorias de Freud. Vá que conhecesse os trabalhos que no seu tempo se faziam sobre as actividades subconscientes. A idea, porém, de comparar o estylo a uma união de palavras determinadas por impulsos sexuaes, com arę de despreoccupação de um cerebro genial, que não se dá ao trabalho de aprofundar e desenvolver as suas intuições.

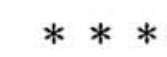

Emquanto M. de Assis se divertia a celebrar o casamento de Sylvio com Sylvia, Sigismundo Freud, em Vienna, vinha como um schrapnell modificar a orientação da psychiatria. Partindo do estudo da historia, chegava a concluir que os factores do dynamismo psychico, na sua grande maiória, são inconscientes e de natureza sexual. E que, tanto arte, como molestia mental, e outros phenomenos psychologicos não passam de manifestações mais ou menos disfarçadas desse instincto. 
Era em 1895. Freud assistia a Breuer, outro medico viennense, no tratamento de uma hysterica, que apresentava entre outros symptomas, uma inhibição dos movimentos do braço sempre que tentava beber um copo dagua. Tinha uma sede intensa, mas assim que chegava o copo aos labios, repellia-o como se estivesse hydrophoba.

Um dia, tendo sido hypnotisada pelos dois medicos, contou-lhes que vira tempos atraz o cãosinho da sua governante beber agua num copo de seu uso. Sentira profunda repugnancia, mas, por polidez, reprimira a sua colera. Desde então tinham surgido em søena os phenomenos puthiaticos. Terminada a confissão, a doente teve uma explosão de colera, pediu em seguida a beber, bebeu uma grande quantidade de agua, e accordou com o copo nos labios. Estava curada. O que prova a relação intima do symptoma com o sentimento recalcado.

Freud proseguiu sosinho nas suas investigações. Um outro caso de hysteria, que muito concorreu para a sua concepção sexualista das nevroses, é o seguinte:

Certa moça apresentava symptomas hystericos, que datavam do dia em que morrera uma sua irmã recentemente casada. Empregando os seus methodos de exploração do inconsciente, Freud descobriu que ella amara o cunhado, sem o saber. E, contemplando a morta, atravessara-lhe o cerebro a idea de que elle estava livre e poderia desposal-a. Esta idea revoltou-a e foi immediatamente recalcada no seu inconsciente. E lá ficou ella com todo o seu potencial a determinar o quadro hysterico. Que não era senão o resultado da lucta de forças reprimidas, como os principios moraes, imprimidos pela educação.

Da hysteria Freud passou ás outras nevroses. Em todas achou sempre uma carga affectiva reprimida, procurando manifestar-se por meio dos symptomas.

Explicou depois outros phenomenos psychologicos: esquecimento de palavras, lapsus linguae, actos falhados. Tudo manifestações de sentimentos reprimidos no inconsciente. Ex. um official vae saudar um superior, e troca uma palavra de elogio por um insulto. Porque inconscientemente, ou mesmo conscientemente, tinha inveja do superior.

Foi incansavel o psychiatra viennense. Despiu o avental, enfiou-se numa toga de aruspice. Passou a interpretar sonhos. Annotou as suas producções oniricas, analysou-as, dissecou-as. Muniu-se de vasto stock de sonhos de individuos normaes e nevroticos. E concluiu que o estudo dos sonhos esclarece largo campo da vida psychica inconsciente. O sonho é tambem a expressão de um desejo. Reprimido ou não. Geralmente inconfessavel. Sua linguagem é, por isso, symbolica. Sua interpretação, um decifrar de symbolos, é uma das bases do methodo psychanalytico. 
A linguagem symbolica é a primitiva, peculiar ao que sonha e ao poeta. Dahi o chamar-se a este sonhador. E, tambem, a expontaneidade caractedistica da verdadeira poesia. Suas palavras, "abelhas de ouro" producto da acção immediata das cousas sobre o artista Funç̧ão do meio, tomam os seus caracteristicos, concretisam-se, tornam-se creações.

Ha na technica psychanalytica um processo de exploração mental de importancia muito grande. E' a "livre associação" Adeante fallarei sobre elle. Basta por ora dizer que o analysta, com o seu emprego, obtem do paciente um amontoado de ideas apparentemente desconnexas, vindas expontaneamente á consciencia. Muitos poemas modernos lembram experiencias de livre associação. E' por isso que todo mundo acredita ser muito facil escrever uma poesia moderna (futurista). Deve-se, porém, ter em mente que as boas qualidades do ovo são infinitamente mais indispensaveis para elle ser tomado crú, "à l'huître", do que para um omelete. Parodia do que dizịa o Visc. de Santo-Thyrso a respeito de ostras e mulheres.

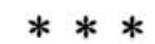

A experiencia de associação livre consiste no seguinte. $\mathrm{O}$ analysta colloca o paciente em posição commoda, num ambiente propicio á meditação. Ordena-lhe que concentre a sua attenção por alguns segundos sobre uma idéa que lhe suggere, e deixe em seguida funccionar livremente o seu mechanismo associativo. Começa então no cerebro do individuo uma dança vertiginosa, ora burlesca, ora macabra, entrecortada de pausas, e em que tomam parte os figurantes os mais disparatados. Conceitos de moral, bombas de gazolina, omnibus da Light, etc. Rapido a principio, o bando vae aos poucos alentando o passo. As pausas tornam-se mais numerosas. Em dado momento uma dellas ameaça tornar-se indefinida. $\mathrm{O}$ paciente diz que não lhe vem nenhuma idéa á consciencia. Com um pouco de habilidade o analysta mostra-lhe que não são as ideas que faltam. Mas, que uma idea, ou immoral, ou exotica, ou mesmo insignificante quiz fazer parte da sarabanda, no que foi impedida, resultando dahi a sensação de vasio intellectual. Cortou-lhe o passo a censura, policia de costumes cerebral, personificação dynamica dos principios moraes, estheticos, e outros que a educação conseguiu infundir no troglodyta do seculo XX. Descoberto o intruso que perturbava a marcha da experiencia, garantida a sua entrada na consciencia, seguem-no muitos outros do mesmo quilate.

Nesse meio heterogeneo vae exercer-se a argucia do analysta. Por intuições, raciocinios, palpites, chega a um grupo de representações possuindo grande carga de energia affectiva. Um complexo. A energia que nelle se accumula é geralmente sexual, a libido, como a chama Freud. $\mathrm{O}$ seu potencial nesses grupos representativos é elevado, 
e faz com que elles se procurem manifestar em sonhos, nevroses, creações artisticas, actos de heroismo, etc.

Ahi a humanidade em peso protestou. Offendeu-se por compararem um grande acto de vandalismo, de carnificina, a que chama heroismo, a simples manifestação erotica.

O symptoma da molestia nervosa, as producções oniricas, etc. são derivativos da libido accumulada nos complexos. O artista opera a transfusão dessa energia na obra de arte. A arte é uma optima valvula. Ha outras: - trabalho muscular, esporte, obras de caridade. Certos homens de genio concentraram toda a sua libido em creações: Newton, Leonardo.

Lombroso dizia:

"O verdadeiro homem normal não é nem o letrado, nem o erúdito; é o homem que trabalha e que come: fruges consumere natus"

Psychanalyticamente, para ser completo, precisar-se-ia accrescentar mas talvez seja inconveniente.

$$
* * *
$$

Ha outras forças determinantes da actividade humana, além do instincto sexual. Por exemplo, as pessoaes, ou "Ichtriebe" de Freud.

A creança já possue a sua vida sexual, por signal que bem complexa. Constitue-n'a a excitação adequada de certas partes do corpo, como a bocca, o anus, a urethra; tem prazer sexual ao mammar, defecar, urinar. Esta primeira phase em que o individuo se satisfaz á custa do proprio corpo, é de auto-erotismo. Ha tambem outras manifestações que exigem a intervenção duma pessoa extranha: prazer de fazer soffrer (sadismo), de soffrer (masochismo); e actividades que determinam a escolha de um objecto (fixações). Mas, com o avançar da creança em annos, essa vida sexual se organisa. "As tendencias se submettem á supremacia da "zona genital" e a "necessidade de uma pessoa extranha expulsa o auto-erotismo"

Mas, para chegar a este resultado, são necessarios muitos recalcamentos, a ruptura de muitas fixações. E preciso muita força dos principios imprimidos pela educação para que quando chegue o periodo da puberdade, as actividades sexuaes tendam a tomar o seu curso normal. Qualquer parada num dos estados primitivos produz uma perversão (sadismo, mastuberçação, homosexualidade). E' nessas epocas infantis, no organismo psychico ainda moço, plastico e hypersensivel que as influencias exteriores são mais capazes de actuar, determinando recalcamentos, formação de complexos, que podem ter um resultado desastroso para o futuro do individuo. 
O sexualismo infantil é um dos pontos mais debatidos da doutrina de Freud. Muitos quizeram identificar o prazer sexual infantil de que elle fala com o prazer da satisfação da fome, do esvasiamento do recto, etc. Foi então creado o termo "pansexualismo", reduzidas todas as manifestações physiologicas e sexuaes. Freud protestou. Distinguia os dois prazeres. Um, devido ao exercicio normal duma funcção, o outro, complementar do primeiro, e sexual. O primeiro permanece inalteravel durante toda a vida. O segundo, como se viu, na puberdade desapparece, ou passa a uma segunda plana, devido á supremacia da "zona genital"

Pode-se até certo ponto dizer que o sexualismo infantil é mais diffuso do que o adulto. E o sexualismo feminino, mais do que o masculino. Portanto, mais delicado. E' um instrumento que necessita para uma boa execução de um virtuose perfeito. Por isso que os. D. Juans são relativamente pouco numerosos.

$* * *$

A psychanalyse tem procurado explicar os caracteres raciaes. Cada raça tem o seu systema de repressão e sublimação. O exemplo. mais citado é o da raça ingleza. Seu elevado senso moral, sua pudicicia, seu gosto pelos esportes, sua calma, são, dizem, signaes de fortes repressões, de sentimentos recalcados, que procuram exteriorizar-se. A sublimação caracteriza-se, na arte ingleza, por um equilibrio quasi perfeito entre o realismo e o idealismo. O "humour" inglez é outro processo interessante de sublimação.

$\mathrm{Na}$ raça norte-americana encontra-se muito do temperamento inglez; mas, o seu dynamismo portentoso é o melhor derivativo da sua libido. Temos ahi, além de outras, a influencia do meio, que indubitavelmente dá novas directrizes ás operações de accomodamento da libido ás necessidades da vida civilizada.

Caracteristico é o que se deu na passagem da raça portugueza ao "typo provisorio" esboçado aqui no Brasil. São conhecidas as tendencias realistas do portuguez, em arte, em amor, em tudo.

Parece que a temperatura um tanto elevada do nosso paiz permittiu que a libido sublimada se condensasse nessas formas solidas. $\mathrm{O}$ espirito do brasileiro permanece nas altas camadas do ideal. Em amor, em arte, em sciencia. Em sciencia principalmente. Uma simples anomalia mascular, encontrada no decurso de uma dissecção, pode engendrar no cerebro do estudante epopeas grandiosas sobre a origem das especies.

Estas considerações theoricas podem ser interessantes. Mas no fundo têm pouco valor. Porque, tanto vale dizer que o americano é pratico, o hindú metaphysico, como que o primeiro sublima sua 
libido em manifestações praticas, o segundo em cogitações metaphysicas. O bom seria conhecer as causas desses phenomenos, para poder reproduzir um ou outro á vontade.

Freud propõe-se a curar grande numero de nevroses com o emprego do seu methodo. Retira os complexos da sombra do inconsciente, "substitue o mechanismo automatico, portanto, insufficiente, da repressão, por um juizo de condemnação moral, feito com o auxilio das mais altas instancias espirituaes do homem; é em plena luz que se triumpha do desejo" Quando é possivel o triumpho. A therapeutica psychanalytica não é, comprehende-se, assim tão simples. As curas duram mezes e mezes. E, muitas vezes, o doente sae apenas melhorados. Dizem mesmo varios autores que as recidivas são frequentes e graves. Ha, no entretanto, em Berlim uma polyclinica psychanalytica, dirigida pelo Dr. Eitingon. Esse medico assegura que nos casos tratados na sua clinica até hoje a percentagem de curas é de $30 \%$; os $70 \%$ restantes saem melhorados.

$\mathrm{Na}$ França divergem muito as opiniões sobre o valor da therapeutica psychanalytica. Já não falando da parte philosophica da doutrina de Freud.

$\mathrm{Na}$ America do Norte o interesse pelo assumpto é intenso. Diz o prof. Oberndorf, de Nova York, que isso é devido ao "great American urge for novelty" Outros, mais malignos, dizem que é porque os americanos tem um deficit de espirito critico.

Entre nós a novidade tambem attrahiu os espiritos cultos. $\mathrm{O}$ jargão psychanalytico já faz parte indispensavel das discussọes de todos os que se reputam modernos e instruidos. Não conheço, porém, tentativa seria no sentido de verificar-se o valor da therapeutica psychanalytica, ou estudos originaes sobre as questões por ella suscitadas. Não quero dizer que não haja. Este Brasil é muito grande. E espero ainda ver muito annuncio assim:

"Tratamento psychanalytico; curas semanaes de desintoxicação mental, com augmento sensivel das energias viris; cura radical da demencia precoce, etc."

Mas, inquieta-me um phenomeno, a que os psychanalystas deram o nome de "transfert" Depois de alguns mezes de tratamento, o doente, por assim dizer, transfere a affectividade accumulada nos complexos para a pessoa do medico. Affeiçoa-se a elle. Ora, aqui neste paiz qual será o futuro de um gynecologo que queira fazer as suas doentes aproveitarem dos beneficios da psychanalyse? 